\title{
Smoke Control of Fires in Subway Stations*
}

\author{
Falin Chen and Shin-Chang Guo \\ Institute of Applied Mechanics, \\ National Taiwan University, \\ Taipei, Taiwan 106, R.O.C.

\section{He-Yuan Chuay} \\ SinoTech Engineering Consulting Co., \\ 171 Nanking E. Road, 5 Sec., \\ Taipei, Taiwan 105, R.O.C.

\section{Shen-Wen Chien} \\ Department of Fire Science and Administration, \\ National Central Police University, \\ Taoyuan, Taiwan 333, R.O.C. \\ Communicated by H.J.S. Fernando
}

Received 12 August 2002 and accepted 22 October 2002

Published online 17 February 2003 - (C) Springer-Verlag 2003

\begin{abstract}
We investigate the effectiveness of the smoke control scheme of the Gong-Guan subway station (GGSS), a typical subway station of the Taipei Rapid Transit System and whose mechanical control systems are also standard in modern subway station design. Three-dimensional smoke flow fields under various kinds of fires are computed by computational fluid dynamics techniques and the results are illustrated on various cross-sectional planes. Results indicate that the stack effect plays a deterministic role in smoke control when a fire occurs near the stairwell; under such circumstances, no mechanical smoke control is necessary. When a fire occurs in other places, such as at the end or the center of the platform, the current mechanical control schemes of GGSS are effective; namely, the smoke can be well controlled, either it is confined to a small region or is evacuated from the station, leaving the four exits free of smoke so that the passengers can escape through them. The effect of the platform edge door (PED) on smoke control is also investigated. With the PED, the effectiveness of the present smoke control system for fires occurring on the chassis of a train, a serious fire in the subway station, increases. We also propose an innovative smoke control scheme with a PED, which turns out to be much more efficient in evacuating smoke than that currently used. This study provides both valuable information for the design of passenger evacuation routes in fires as well as criteria for the design of a smoke control system for subway stations.
\end{abstract}

* The financial supports for this research from both the SinoTech Engineering Consultant Inc. and the National Science Council under Grant NSC 89-2212-E-002-61 are gratefully appreciated. 


\section{Introduction}

Fires in subway stations happened frequently in history, especially in the past two decades when the subway has become a major transportation scheme in metropolitan areas. The cases listed in Table 1 [1] are only a few examples which have claimed the lives of passengers. Some of the cases are pure accidents, while others were caused by vandalism and terrorist attacks. Two well-known major accidents have made indelible imprints on our memories, both causing a large number of victims: One happened at London's King's Cross subway station and one in the Baku (the capital of the Republic of Azerbaijian) subway tunnel. The fire at King's Cross subway station happened on 18 November, 1987, causing one death and 47 serious injuries. The fire at Baku on 29 October, 1995 was even more serious, the hot air and toxic smoke killed 337 people and left 227 seriously injured. From the results obtained from a computational fluid dynamics (CFD) simulation of the King's Cross fire [2], it was found that smoke movement in this complicated station could hardly be predicted and that smoke control is crucial in a fire emergency; more precisely, for example, buoyant smoke may move rapidly through the stairwells, blocking the passages through which passengers are supposed to evacuate.

Table 1. A few examples of fire accidents in subway systems [1].

\begin{tabular}{lll}
\hline Date & City & Details \\
\hline March 1964 & New York & Train on fire and then the equipment, 3 persons injured \\
January 1968 & Tokyo & Break of train burned, 11 persons injured \\
September 1970 & Tokyo & Restaurant on fire, smoke spreads into subway \\
February 1976 & London & Platform equipments on fire, electricity off, nine trains stop in tunnels, 25 persons injured \\
September 1979 & New York & Transformers on fire, 178 persons injured \\
January 1979 & San Francisco & Spark from train ignites fire, 1 person died and 44 injured \\
August 1983 & Nagoya & Station transformers on fire, 700 persons escaped into tunnel and 1 firefighter died \\
November1984 & London & Warehouse of platform on fire, damaged the ceiling and tunnel wall, 18 persons injured \\
July 1985 & London & Escalator on fire, 1 person died and 47 injured \\
December 1985 & London & Escalator on fire, 200 persons were evacuated \\
November 1987 & London & Escalator on fire, smoke spreads in station, 84 persons injured \\
May 1994 & Taipei & Transformers on fire, smoke spreads into the two stories of the station, 10 firefighters injured \\
October 1995 & Baku & Train on fire, 337 persons died and 227 injured. \\
April 2000 & Washington, DC & Electrical cable burned, 273 passengers on train were evacuated safely \\
\hline
\end{tabular}

In fires at subway stations, the most immediate threat to passengers' lives is not direct exposure to fire, but smoke inhalation because it contains hot air and toxic gases. To understand the mechanisms driving the motion of smoke is therefore an important issue for fire safety, and confirmation of the effectiveness of the smoke control systems in subway stations is also a necessity before the station is opened for public service. We do this confirmation for the Gong-Guan subway station (GGSS, see Figure 1) although it has been opened for service since 1998. To do this, we investigated the smoke propagation in GGSS for various kinds of fires. GGSS is a typical midway subway station of the Taipei Rapid Transit System (TRTS), which currently consists of 6 lines and 63 stations, totally $86.8 \mathrm{~km}$, serving to commute more than 1 million passengers per day in Taipei's metropolitan area. In the second phase of construction, there will be seven new lines to add into the TRTS, rendering it one of the largest metropolitan transportation systems in the world. GGSS, commuting more than 20000 passengers per day, is equipped with three mechanical smoke control systems, which are standard equipment for modern subway stations. The analysis of the smoke propagation of this study can accordingly count as a representative case for the TRTS and other modern subway systems.

Accordingly, we investigate the effectiveness of the smoke control systems of GGSS: the tunnel ventilation fan (TVF), the under platform exhaust (UPE) system, and the smoke evacuate gate (SEG), see Figure 1(a). The CFD approach is employed to investigate the three-dimensional smoke flow field of GGSS. Special emphasis is placed on the evolution of smoke propagation under smoke control, and an innovative smoke control scheme is also proposed. We note also that, in fires occurring in an enclosure such as a subway station, a natural convection phenomenon named the "stack effect" may play a significant role in smoke 


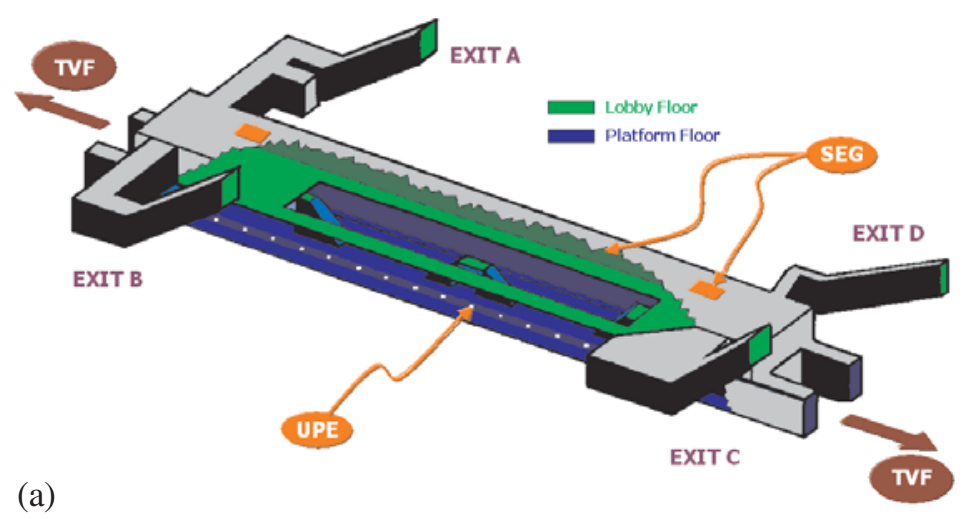

(a)

\section{(b)}

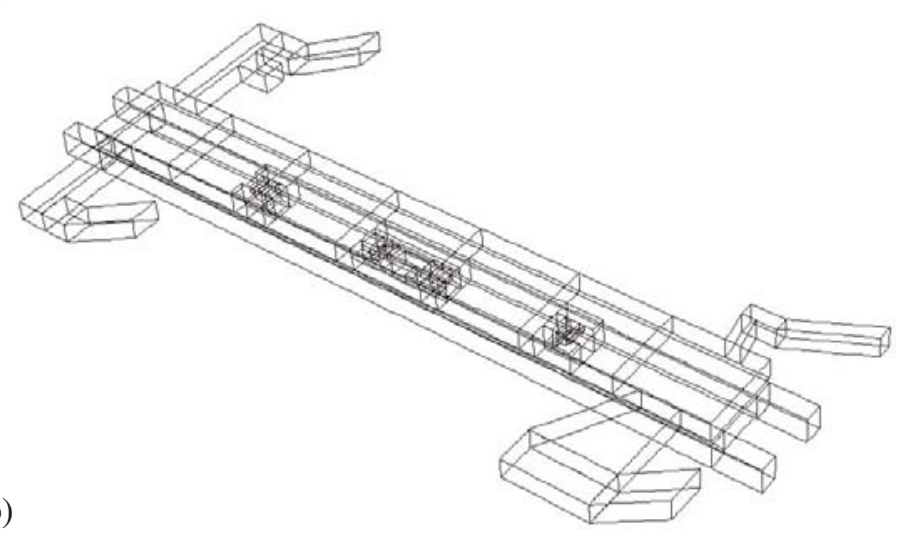

Figure 1. (a) A schematic drawing of the Gung-Guan subway station. Exit A goes to Shuei-Yuan market, both Exits B and C go to the campus of the National Taiwan University, and Exit D goes to the Da-Xue-Kou restaurant area. In the station there are four stairs and two escalators connecting the platform and the lobby floors: two stairs are located in the center and one stair and one escalator on each side. The two black arrows account for the direction of the wind driven by the TVF. Under the platform floor, there are 36 openings of the UPE serving to exhaust the air near the rails. On the ceiling there are eight SEGs serving to evacuate the air attached to the ceiling. (b) The computational grid of GGSS. There are 125 grid-blocks in the computational domain. In each gridblock a uniform grid is employed. The number of grids of each block varies, depending primarily upon the flow structure within the block. A finer grid is prescribed for the block covering a flow of a more complicated structure, such as those including fire, corner, stair, and so on. There are more than 300000 grid-points in the computational domain.

propagation when no mechanical system is engaged. This is because in most enclosures there are various kinds of structural vertical spaces through which the buoyancy force of hot smoke is enhanced. The pressure difference induced by the stack effect can be much larger than that due to other driving forces, such as the expansion of combustion gas, wind effect, and so on [3]. As soon as the stack effect forms, the smoke generated in an enclosure will move towards and into vertical shafts, such as the stairwell, the shaft of an elevator, or the vertical shaft of a ventilation system, becoming an important phenomenon which the design of a smoke control system has to consider seriously. Accordingly, the stack effect is also one of the major issues studied here.

We introduce the architectural configuration and the smoke control systems of GGSS in Section 2. A detailed description of the mathematical model and relevant boundary conditions are given in Section 3. In Section 4 we show many typical examples of smoke propagation in GGSS. Three-dimensional computational results are illustrated by the temperature and velocity vector distributions on various cross-sectional planes. In Section 5 the stack effect on smoke propagation is discussed, emphasis is placed on the characteristics of this natural convection and results may cast a general rule which the design of smoke control systems in subway stations can follow. Section 6 is the major part of the paper, in which the effectiveness of the smoke control system of GGSS is discussed extensively. In Section 7 the effect of the platform edge door (PED) on smoke control is discussed. A fire which occurs on the chassis of train is considered and the superiority of a PED on smoke control can be clearly seen. It turns out that with a PED an innovative smoke 
control scheme of great performance can be made. Finally, in Section 8 several concluding remarks are drawn.

\section{Architecture and Smoke Control Systems of GGSS}

As a typical midway station of the TRTS, the GGSS has two floors: the platform floor at the bottom, in which an island platform sits between the two rails of opposite direction (Figure 2(a)), and the lobby floor at the top, in which two hallways (Figure 2(b)) at the two ends of the floor connect the lobby and four stairwells (or exits, Figure 2(c)). The length of the station is $142.1 \mathrm{~m}$ and the width is $17.9 \mathrm{~m}$. The height of the lobby floor is $4.15 \mathrm{~m}$ and that of the platform floor is $5.15 \mathrm{~m}$. Far the beauty of the interior of the station and the relaxation of mental pressure due to the space limitation of the platform floor, a large area at the center of lobby floor is cut off, but two $2 \mathrm{~m}$ wide passages remain on the edge (Figure 2(a)). This cut-off of the lobby floor, unfortunately, enhances the buoyancy force of hot smoke, making smoke control in GGSS more difficult.

To ensure the smoke is well controlled during fires, the station is equipped with three mechanical systems to evacuate smoke (Figure 1(a)): (1) The TVF is located in the tunnel near the two ends of the platform floor, sucking air into the tunnels and evacuating it to the road surface, inducing an approximately $5 \mathrm{~m} / \mathrm{s}$ wind into the tunnels. (2) The UPE is located below the platform, having 36 openings along the two sides of the platform (18 on each side), inducing an approximately $2 \mathrm{~m} / \mathrm{s}$ flow into the opening. (3) The SEG is located on the ceiling of the lobby floor, having eight gates uniformly distributed along the ceiling, inducing an approximately $2 \mathrm{~m} / \mathrm{s}$ flow into the gate; see the two SEGs (the squares) shown in Figure 2(d). As a fire occurs, the person in charge in the control center will observe both the location and the development of the fire and then decides which system should be engaged to evacuate the smoke [4]. There is another smoke control setup, named the smoke blocking wall (SBW), which is necessary to conform with the fire-safety regulations in Taiwan. There are seven SBWs dividing the ceiling into eight zones. The SBW hangs down from the ceiling

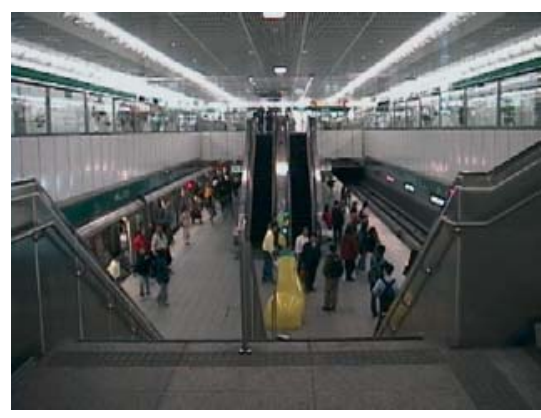

(a)

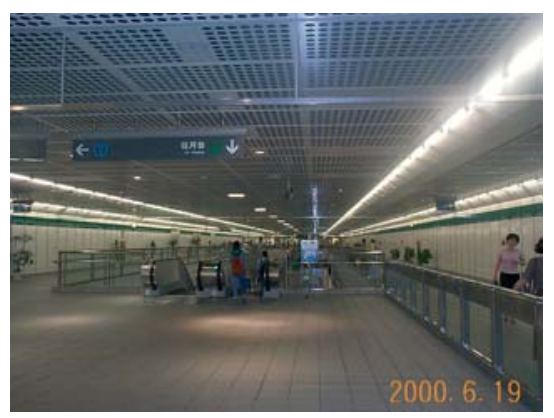

(b)

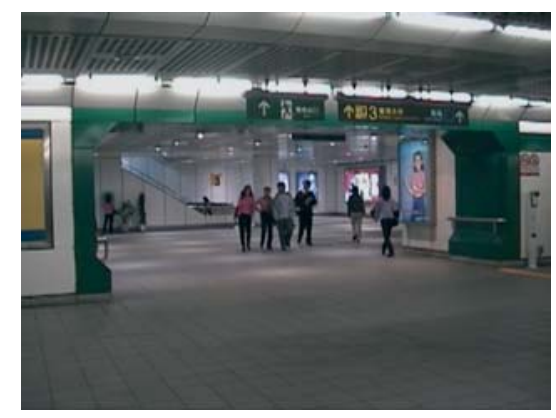

(c)

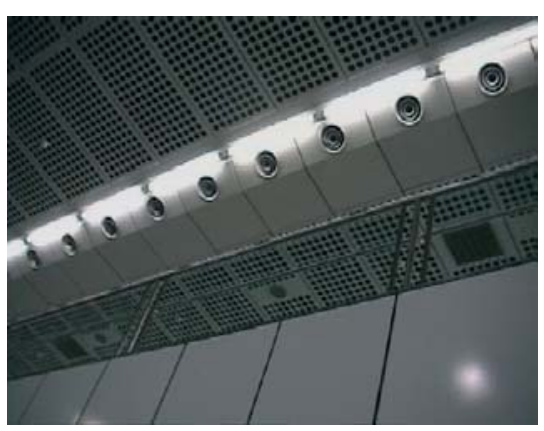

(d)

Figure 2. Photographs of the interior of GGSS. (a) A view from the top of the stairs connecting the lobby and the platform floors. It is seen that the cut-off area of the lobby floor presents the interior of the station from becoming a connected large open space. (b) A view from the hallway of the lobby floor close to Exits C and D. At the top of the photograph is the vertical smoke blocking wall (SBW) made of plexiglass. (c) A view looking into the entrance of Exit C, the largest exit of GGSS. (d) The ventilation gates (circular, nine in the picture) and the smoke exhaust gates (SEG, square, two in the picture) on the ceiling. 
and is approximately $1.3 \mathrm{~m}$ high. These walls are designed to confine the smoke within the smoke zone and this scheme is named the smoke-zone compartment, in which the smoke propagation in the large open space will be damped significantly. The SBW is also considered in the present computations.

The four exits in GGSS go respectively to the campus of the National Taiwan University (Exits B and C) and to Shuei-Yuan traditional market (Exit D) and Da-Xue-Kou, a complex restaurant district (Exit A). All these places are busy areas, so that GGSS serves to commute more than 20000 passengers per day. Each exit has one or two escalators connecting the lobby floor and the surface, forming a space (or stairwell) through which the stack effect may predominate the smoke movement in station fires when no mechanical smoke control is engaged. As smoke moves into the stairwells, evacuation of people from the subway station through these exits is prohibited, dramatically influencing the whole evacuation plan in a fire emergency.

\section{Mathematical Formulation and Numerical Scheme}

To investigate smoke propagation in GGSS, we employ the CFD approach to compute the three-dimensional flow of the subway station. A reliable CFD result regarding smoke movement in fires can be obtained when the following points are treated carefully [5]: (1) The flow in the subway station, especially that near the fire, shall be three-dimensional. (2) A careful choice of both the turbulent model and the corresponding input parameters is crucial. (3) The fire can be taken as a source of heat and smoke (accounted for by $\mathrm{CO}_{2}[6]$ ) in which no combustion is considered. To meet these requirements, a computer code named CFX4 developed by the AEA Co. of England is employed to solve the flow field. In this code a finite volume numerical scheme is employed.

We note that the turbulent model employed in the CFX4 code is the standard $k-\varepsilon$ model, which serves well to simulate the mean flow field. A detailed turbulent structure of the flow can be obtained when a proper modification of the model has been made. Some specific modifications are necessary for some flows of a special structure, for example, flow near the sharp corner and flow near the fire with a strong chemical reaction. A large volume of research on the turbulence modeling of flame had been reviewed by Libby and Williams [7]. The effect of turbulence modeling on the computational results of buoyant diffusion flames has also been discussed by Liu and Wen [8]. In the present paper we have no intention of emphasizing the detailed structure of the turbulent flow. However, instead, emphasis is placed on investigation of the efficiency of the smoke evacuation schemes of GGSS. As a result, the mean flow is the major part to be examined while the detailed turbulent structure, having a minor effect on the smoke movement, can therefore be neglected. Accordingly, the standard $k-\varepsilon$ turbulence model considered in the CFX4 code to some extent meets the purpose of this paper.

The mathematical model and relevant boundary conditions are shown in the following, for details of the numerical approach refer to the manual of CFX4. The governing equations are: [9]

the continuity equation

$$
\frac{\partial \rho}{\partial t}+\nabla \times(\rho \boldsymbol{U})=0
$$

the momentum equations

$$
\frac{\partial}{\partial t}(\rho \boldsymbol{U})+\nabla \times(\rho \boldsymbol{U} \boldsymbol{U})=\boldsymbol{B}+\nabla \times \boldsymbol{\sigma},
$$

the energy equation

$$
\frac{\partial}{\partial t}(\rho H)+\nabla \times(\rho \boldsymbol{U} H)=\nabla \times(\lambda \nabla T)+\frac{\partial P}{\partial t}+\boldsymbol{B} \times \boldsymbol{U}+\nabla \times(\tau \times \boldsymbol{U})+Q,
$$

and the mass generation equation

$$
\frac{\partial}{\partial t}\left(\rho Y_{C}\right)+\nabla \times\left(\rho \boldsymbol{U} Y_{C}\right)=\nabla \times\left(\kappa \nabla Y_{C}\right)+S_{C} .
$$


In above equations, $\rho$ accounts for the density, $\boldsymbol{U}$ is the velocity vector $(u, v), \boldsymbol{B}$ is the body force, $\sigma=-P \boldsymbol{I}+\mu_{e}\left(\nabla \boldsymbol{U}+\nabla \boldsymbol{U}^{T}\right)-\left(\frac{2}{3}\right) \mu_{e}(\nabla \times \boldsymbol{U}) \boldsymbol{I}$ is the stress tensor, $H$ is the total enthalpy, $\lambda$ is the heat conductivity, $T$ is the temperature, $P$ is the pressure, $\tau=\mu_{e}\left(\nabla \boldsymbol{U}+\nabla \boldsymbol{U}^{T}\right)-\left(\frac{2}{3}\right) \mu_{e} \nabla \times \boldsymbol{U}, Q$ is the heat source, $Y_{C}$ is the mass fraction of $\mathrm{CO}_{2}, \kappa$ is the mass diffusivity, and $S_{C}$ is the mass source. Note that the use of the $k-\varepsilon$ model yields $\mu_{e}=\mu_{t}+\mu$ and $\mu_{t}=\rho C k^{2} / \varepsilon$, where $\mu$ is the dynamic viscosity, $C=0.09$ [6], $k$ is the local kinetic energy of fluctuation motion, and $\varepsilon$ is the energy dissipation rate. The values of these parameters are the same as those used in [5], they are respectively $\sigma_{k}=1, \sigma_{\varepsilon}=1.217, \sigma_{h}=1, C_{1}=1.44, C_{2}=1.92$, $C_{3}=0$, and $C_{\mu}=0.09$. The notations of these parameters are also the same as those used in [5], to which the reader is referred for their physical meanings.

To solve the above equations, we employ the CFX4 code. The computational domain is the threedimensional GGSS (Figure 1). Note that, since in this paper we do not consider combustion, the fire is considered as the source of heat and smoke. As found from the product analysis of combustion, a fire having a heat release rate $5 \mathrm{MW}$ is accompanied by a smoke generation rate $1.4 \times 10^{5} \mathrm{ppm} / \mathrm{s}$ [10], both are fixed as this in the paper except in Section 7 where a fire of $10 \mathrm{MW}$ and $2.8 \times 10^{5} \mathrm{ppm} / \mathrm{s}$, simulating a fire on the chassis of a train, is considered. The computational field of GGSS is embedded with a multigrid system, in which the space is divided into 125 blocks (Figure 1(b)). In each block the grid is uniformly distributed, but the grid size of the block can be different to each other, depending on the characteristics of the flow. For example, the grid in the block containing or near the fire shall be finer than those away from the fire; the grid near the corner where the flow changes rapidly shall also be finer than those without a geometrical change. It turns out that the number of grids for GGSS is more than 300000 .

To compute the smoke flow in GGSS, the following boundary conditions are prescribed. Constant pressure is prescribed on the boundaries of the four exists and the four tunnel entrances, because no approaching train or no pulsating air movement caused by train movement is considered. On the same boundaries, the continuities of heat and mass fluxes are also prescribed. On the solid walls, a non-slip condition, constant temperature, and zero smoke flux are assumed. When the stack effect is investigated, since it is a natural convection phenomenon and no mechanical smoke control system is engaged, all the above boundary conditions are valid. When a mechanical smoke control system is engaged, the following boundary conditions are considered: When UPE is active, a flow of $2 \mathrm{~m} / \mathrm{s}$ into the UPE opening is prescribed. When SEG is active, a flow of $2 \mathrm{~m} / \mathrm{s}$ into the gate is prescribed. When TVF is active, a flow of $5 \mathrm{~m} / \mathrm{s}$ into the four tunnels is prescribed. No radiation is considered in the present model, which under some circumstances may nevertheless have a significant effect on smoke movement when the scale of the fire is large, which may merit further investigation in the future. For each computation, numerical stability and numerical accuracy were checked by changing the number of iterations. Normally, a 20-time iteration or higher is needed to obtain a converged solution. For a fire of $5 \mathrm{MW}$, it takes about 6 hours to run through a case on a PC with a Pentium 4 $1.8 \mathrm{GHz} \mathrm{CPU}$ and $128 \mathrm{MB}$ RAM.

\section{Smoke Propagation in Fires in GGSS}

To illustrate the smoke propagation in GGSS, we begin with the flow in GGSS induced by a fire of $5 \mathrm{MW}$ occurring on the left of the lobby floor (Figure 3), where no mechanical smoke control system is engaged. In this three-dimensional picture, there are five vertical cross-sectional (VCS) planes. In each plane the temperature distribution, represented by colors (Figure 3(a)), and the flow, represented by velocity vectors (Figure 3(b)), are shown. Both the temperature level and the velocity amplitude are accounted for by the color bars above each subfigure, where the temperature ranges from $300 \mathrm{~K}$ (dark blue) or below to $400 \mathrm{~K}$ (orange) or above and the velocity ranges from $0 \mathrm{~m} / \mathrm{s}$ (dark blue) to $5 \mathrm{~m} / \mathrm{s}$ (orange) or larger. The same color level is employed in the following figures of this paper.

Both figures show the results at $t=4$ min: part of the smoke has moved into the center of the lobby floor as well as down to the platform floor, while most of the smoke has moved into the two stairwells to evacuate from the station. It is interesting to note from the velocity vectors in the middle VCS plane (Figure 3(b)) that part of the flow is moving to the left, which is due to the stack effect occurring in the two stairwells on the left. In other words, the hot smoke reaches the two stairwells at the left first, which in turn induces a strong buoyancy flow in the stairwells, making the stairwells become low pressure zones and suck the air out of the 


$\begin{array}{llll}300.0 & 325.00 & 350.00 & 375.00\end{array}$

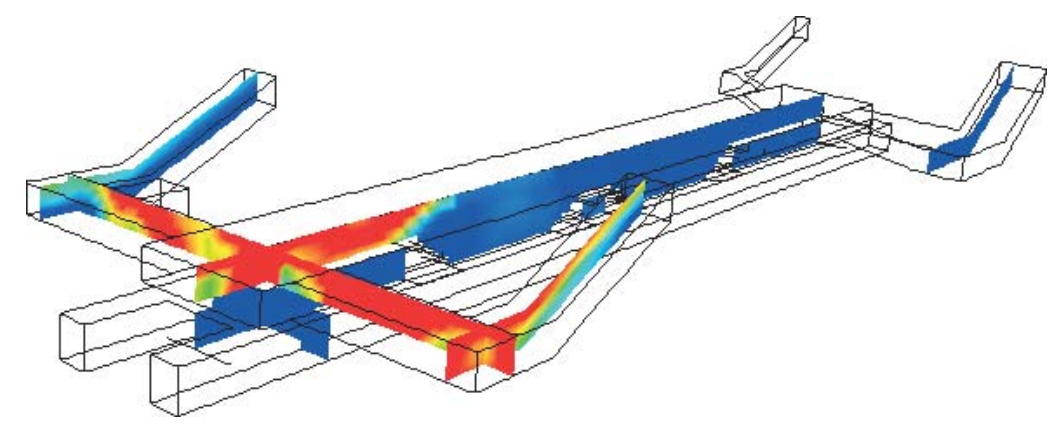

(a)

$\begin{array}{lllllll}0.00 & 1.00 & 2.00 & 3.00 & 4.00 & 5.00 & (\mathrm{~m} / \mathrm{s})\end{array}$

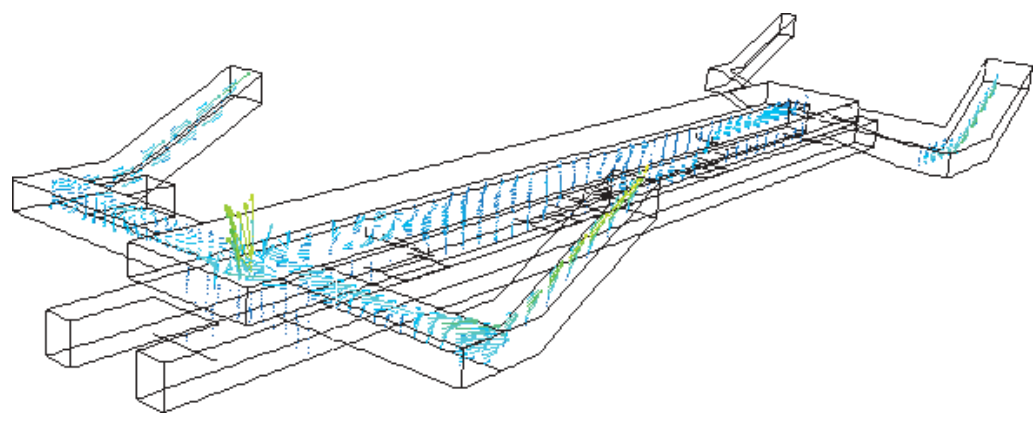

(b)

Figure 3. The three-dimensional stereo view of the smoke distribution in GGSS due to a fire located at the left of the lobby floor. (a) The temperature distribution and (b) the velocity vectors on several VCS planes: one longitudinal VCS passes through the middle of the station, one transverse VCS is located at the left hallway connecting the lobby and the stairwells and two sit at the center of the stairwells.

station. Similar phenomena are also found in other cases under different fire conditions. Details of the stack effect will be discussed in the next section.

Note that, as shown in Figure 3 and other figures of the paper, we will employ mostly the temperature distributions and sometimes the velocity vectors on different cross-sectional planes and at different time steps to illustrate the evolution of smoke propagation in the station. In a qualitative sense, temperature distributions are quite similar to the smoke distribution accounted for by the concentration distribution of $\mathrm{CO}_{2}$, which is primarily because the diffusivities of heat and $\mathrm{CO}_{2}$ are of insignificant difference under the present parametric range considered, so that the propagation of $\mathrm{CO}_{2}$ can to some extent account for that of smoke [5]. Accordingly, temperature distribution can also be interpreted as smoke distribution, or the hot air movement is essentially equivalent to smoke movement.

Figure 4 illustrates a series of pictures regarding temperature distributions on the middle VCS plane from fires at different locations. The results are categorized into three groups: Group A corresponds to a fire located at the right of the lobby floor, Group B to a fire located at the center of the lobby floor, and Group C to a fire located at the right of the platform floor. In each group we present six pictures at different times. In Group D we show the temperature distribution on the horizontal cross-sectional (HCS) plane located $1 \mathrm{~m}$ below the ceiling at $t=5 \mathrm{~min}$. 
Group A

(a) $\mathrm{t}=30 \mathrm{~s}$

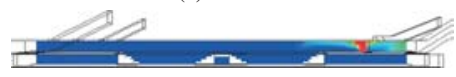

(b) $t=1 \min$

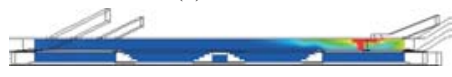

(c) $\mathrm{t}=2 \mathrm{~min}$

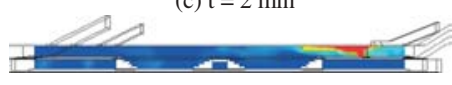

Group B

(a) $\mathrm{t}=30 \mathrm{~s}$

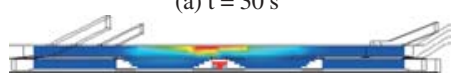

(b) $t=1 \min$

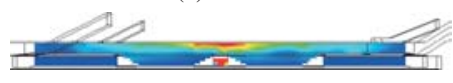

(c) $t=2 \min$

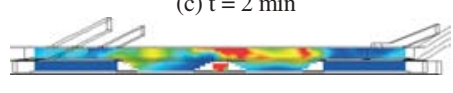

Group C

(a) $\mathrm{t}=30 \mathrm{~s}$

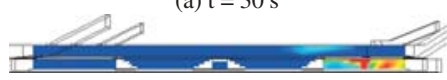

(b) $\mathrm{t}=1 \mathrm{~min}$

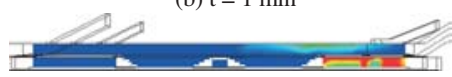

(c) $t=2 \mathrm{~min}$

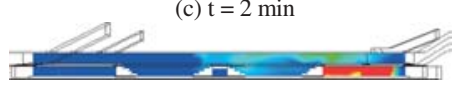

Group D
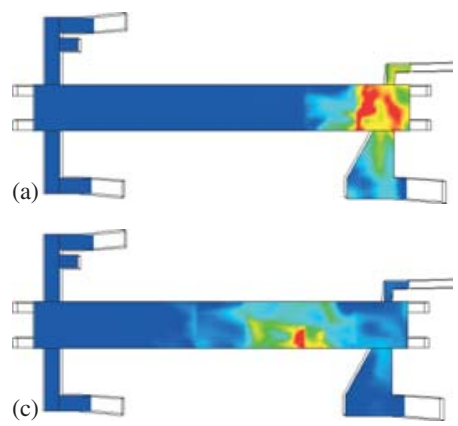

(d) $t=3$ min

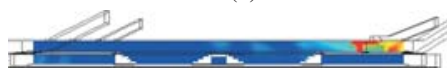

(e) $\mathrm{t}=5 \mathrm{~min}$

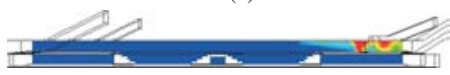

(f) $\mathrm{t}=10 \mathrm{~min}$

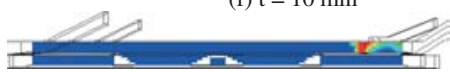

(d) $t=3 \mathrm{~min}$

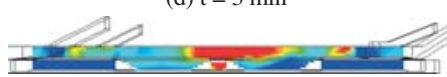

(e) $t=5 \mathrm{~min}$

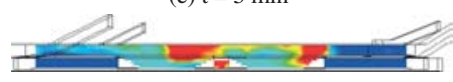

(f) $\mathrm{t}=10 \mathrm{~min}$

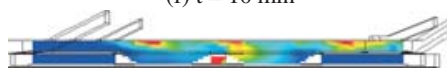

(d) $t=3 \min$

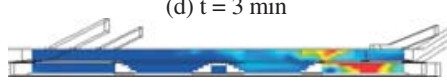

(e) $\mathrm{t}=5 \mathrm{~min}$

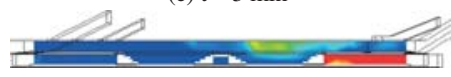

(f) $\mathrm{t}=10 \mathrm{~min}$
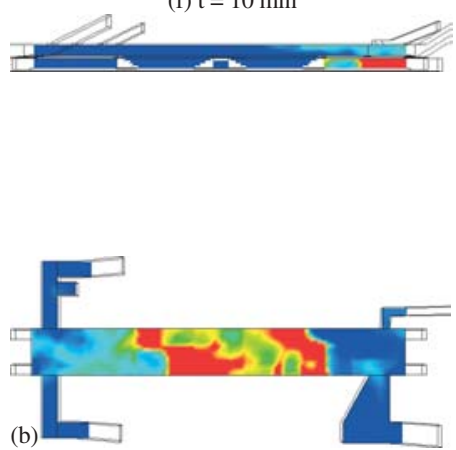

Figure 4. Smoke propagation due to fires at different locations. Groups A, B, and C show the smoke on the VCS plane cutting through the middle of the station, and Group D shows the smoke on the HCS plane located $1 \mathrm{~m}$ below the ceiling. In Group A the fire occurs at the right of the lobby floor, the smoke is evacuated from the station due to the stack effect. In Group B the fire occurs at the center of the lobby floor, the smoke propagates randomly in the station. In Group C the fire occurs at the right of the platform floor, the smoke moves to both the platform and the lobby floor, the stack effect is not so predominant as in $\operatorname{Group} \mathrm{A}$. $\mathrm{D}(\mathrm{a}), \mathrm{D}(\mathrm{b})$, and $\mathrm{D}(\mathrm{c})$ correspond to $\mathrm{A}(\mathrm{e}), \mathrm{B}(\mathrm{e})$, and $\mathrm{C}(\mathrm{e})$, respectively. It is seen that the smoke propagation of Group $\mathrm{B}$ (fire at the center) is the most serious case. 
In Group A the fire occurs at the right of the lobby floor, a small portion of smoke propagates to the left at $t=2 \mathrm{~min}$, but eventually moves back to the right and evacuates out of the station through the two stairwells due to the stack effect. In Group B the smoke propagates rapidly and moves into every corner of the station in a short time, rendering a serious situation threatening the safety of the passengers. In Group $\mathrm{C}$ the fire is located at the right of the platform floor, and the smoke moves into the center of the station within a few minutes. Although the smoke eventually moves back to the right of the station to evacuate, again because of the stack effect, the smoke has stayed in a large part of station for more than $10 \mathrm{~min}$. This has led to a situation where one may not evacuate all the passengers in the station within the 6 min critical limit suggested by the NFPA [11], which is followed by most subway system regulations including the TRTS. In Group D we compare the above three cases by observing the smoke distribution on the HCS plane $1 \mathrm{~m}$ below the ceiling at $t=5 \mathrm{~min}$. It confirms that for a fire located at the center of the station, smoke distribution is most serious and an efficient smoke control scheme is required. When a fire occurs at the right of the lobby floor, the stack effect plays a significant role in evacuating the smoke without the aid of a mechanical ventilation system. When a fire occurs at the right of the platform floor, smoke distribution can be serious. For this case, nevertheless, the existing smoke control system TVF can efficiently evacuate the smoke through the tunnels, as shall be shown in Section 6 .

\section{Stack Effect in GGSS}

The stack effect is a complicated phenomenon in subway stations. The influencing factors can vary widely although, by and large, area and location are the two factors predominating in most situations [4]. To elucidate this, we show two cases of different fire locations in the two groups of Figure 5. In the first case

Group A

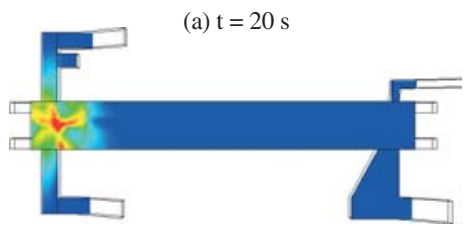

(b) $\mathrm{t}=1 \mathrm{~min}$

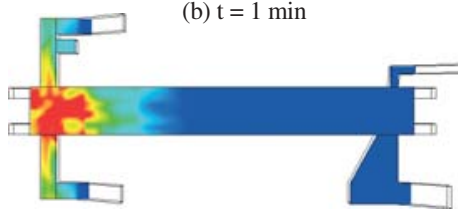

Group B

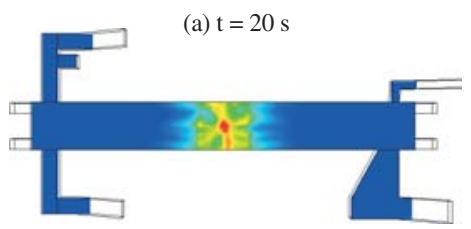

(b) $\mathrm{t}=1 \mathrm{~min}$

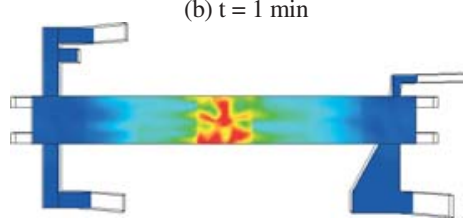

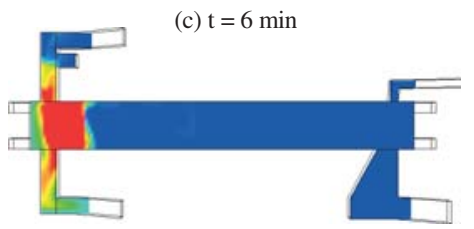

(d) $\mathrm{t}=10 \mathrm{~min}$

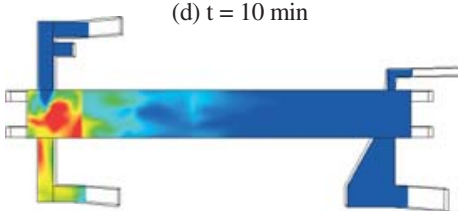

(c) $\mathrm{t}=5 \mathrm{~min}$

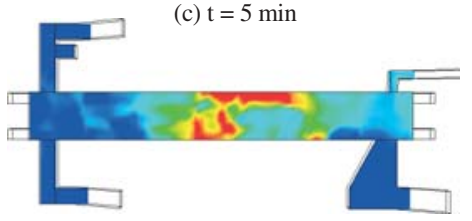

(d) $\mathrm{t}=10 \mathrm{~min}$

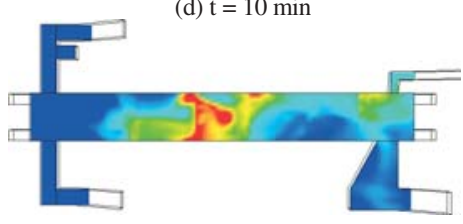

Figure 5. Stack effect on the smoke propagation in GGSS. In Group A the fire occurs at the left of the lobby floor, Exits A and B compete to evacuate the smoke and eventually Exit B predominates. In Group B the fire occurs at the center of the platform floor, Exits $\mathrm{A}$ and $\mathrm{B}$ on the left and the Exits $\mathrm{C}$ and $\mathrm{D}$ on the right compete to evacuate smoke, and the exits on the right eventually predominate. 
(Group A) we impose a fire at the left of the lobby floor. At the beginning of the fire (Figure 5A(a)), most of the smoke moves equally to the two exits on the left of the lobby floor while some of the smoke moves to the right (Figure 5A(b)), but after the smoke starts to evacuate from GGSS from the two exits on the left, the smoke moving to the right is sucked back to the left due to the stack effect (Figure 5A(c)). This is because the motion of the is enhanced in the left exits, inducing a smaller pressure region on the left and thus a horizontal pressure gradient pointing to the left, sucking the smoke to the left afterwards. The above is the first stage of the stack effect, showing the competition between the exits on the left and on the right of GGSS. Then the second stage of the stack effect occurs; namely, the competition between the two exits on the left becomes significant. Eventually, the smoke chooses Exit B to evacuate because (1) Exit B has a smaller area and (2) in front of Exit A there is a space for the lift, which disturbs the movement of the smoke. In brief, at the first stage of the stack effect, the location factor dominates smoke movement, making the smoke move to the left of GGSS. Then at the second stage the area factor takes over, leading to most of the smoke being evacuated from Exit B. At this stage, as shown in Figure 5A(d), Exit B is not wide enough to evacuate all the smoke so that a small amount of smoke is propagating into the station.

In Figure 5B we present the case of a fire located at the center of the platform floor. The smoke moves upwards rapidly, impinges on the ceiling, and propagates rapidly to the two ends of the station (Figure 5B(a)). The smoke reaches the two ends at almost the same time (Figure 5B(b)), while due to the smaller area of Exit $\mathrm{D}$ on the right, the area factor of the stack effect predominates the movement of the smoke, inducing the smoke to move to the right (Figure 5B(c)). Then the two stairwells on the right compete to evacuate the smoke, and obviously Exit D predominates over Exit $C$ because of its smaller area. Nevertheless, because the quantity of smoke is so large that Exit D is not sufficiently large to evacuate all the smoke moving to the right, Exit $\mathrm{C}$ also helps evacuate some of the smoke due to its large cross-sectional area (Figure 5B(d)). This case illustrates that competition occurs in two different stages: the first competition occurs between the exits on the left and the right, and the second competition occurs between the two exits on the right. For both stages the area factor is the sole factor influencing the movement of the smoke.

Note that the stack effect in subway stations can become complicated due to the configuration of the inner space of the subway station, for example the King's Cross station of the London subway system has three floors, so that other factors such as the geometry factor may play a role. Nevertheless, there is a rule-ofthumb of the stack effect that can always be followed: the smoke will evacuate from the exit which it reaches first, and then all or most of the smoke in the station will move towards this exit to evacuate. In other words, the location factor plays a more significant role than the area factor. On the other hand, if there is no location factor, the area factor will predominate the system; i.e., the smoke will evacuate from the exit with the smaller area. However, if these two factors show up simultaneously, the location factor is in general more influential than the area factor.

\section{Examination of Smoke Control Schemes of GGSS}

In GGSS there are three mechanical schemes to evacuate smoke (see Figure 1): TVF, UPE, and SEG. In this section we examine the performance of these smoke control schemes. The case examined is a fire located at the center of the platform floor because it is the most difficult case as far as smoke control is concerned. The results are again categorized into three group: Group A shows smoke propagation without smoke control (Figure 6A); Group B shows the results with an active SEG (Figure 6B); Group C shows the results with an active TVF and UPE, which are turned on simultaneously (Figure 6C); Group D shows two horizontal planes of the case of Figure $6 \mathrm{C}(\mathrm{b})$ regarding smoke distribution in both the lobby and the platform floors (Figure 6D).

Without smoke control (Figure 6A), the smoke generated from the fire at the center of the platform propagates rapidly in the station, creating a dangerous environment to passengers. With an active SEG (Figure 6B), smoke distribution is slightly improved, most of the smoke is confined to the central region of the station but it is still to some extent threatening the passengers because the smoke is quite close to the four exits. This is because the smoke generation rate of the fire is larger than the evacuation rate through the SEG. With an active TVF and UPE (Figure 6C), the smoke is confined to a small region in the center of the station, leaving the four stairwells free of smoke. This is because most of the smoke is evacuated through the TVF and UPE, which can be seen more clearly from Figure 6D. From Figure 6D(a), the smoke distribution on the 


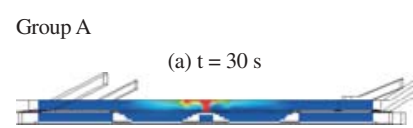

(b) $\mathrm{t}=1 \mathrm{~min}$

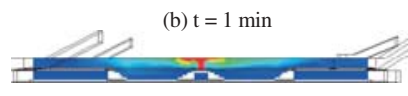

(c) $t=2 \min$

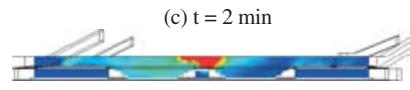

Group B

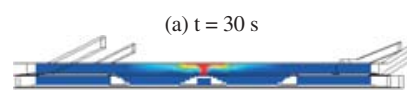

(b) $\mathrm{t}=1 \mathrm{~min}$

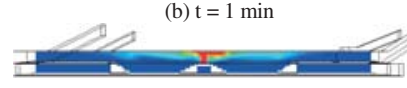

(c) $t=2 \min$

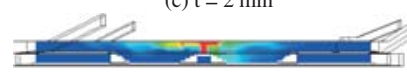

Group C

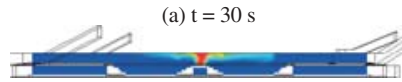

(b) $t=1 \min ($ see Group D)

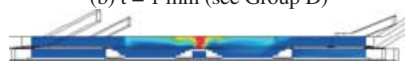

(c) $t=2 \min$
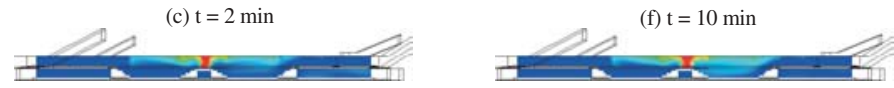

(d) $t=4$ min

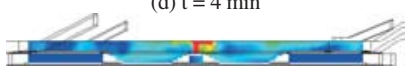

(e) $t=6 \mathrm{~min}$
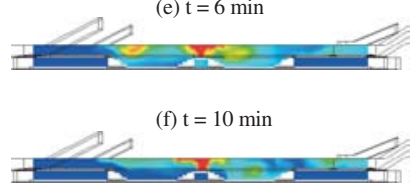

(e) $t=6$ min

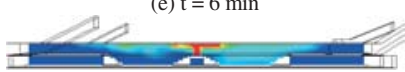

(f) $\mathrm{t}=10 \mathrm{~min}$

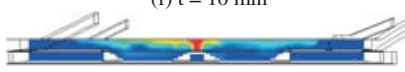

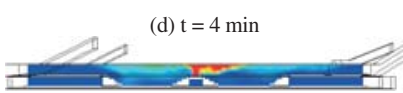

(e) $\mathrm{t}=6 \mathrm{~min}$

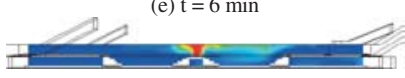

Group D

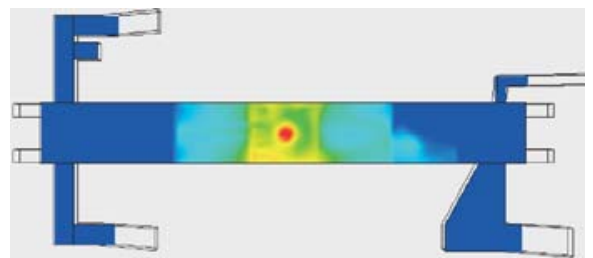

(a)

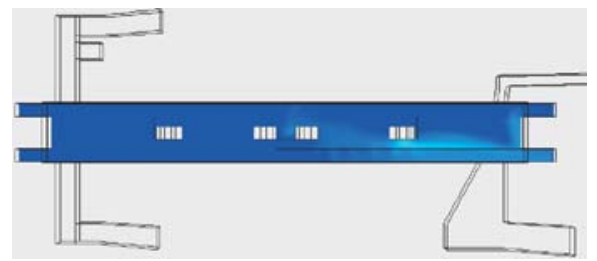

(b)

Figure 6. Effects of smoke control due to different smoke control schemes. In all the cases considered, the fire occurs at the center of the platform floor. In Group A no smoke control system is engaged, the smoke is driven due to the stack effect and is propagating to the right of the station. In Group B the SEG is on, the stack effect is suppressed by the suction of the SEG, which causes the smoke to remain in the central part of the station. In Group C the TVF and UPE are active, a great majority of the smoke is evacuated through the tunnels due to the TVF while a minority of the smoke is evacuated through the openings of the UPE, leaving a small amount of smoke in the central part of the station. Group D shows clearly at $t=1 \mathrm{~min}$ that (a) only a small amount of smoke stays in the station and (b) a strong stream of smoke passes through the tunnels due to the TVF. 


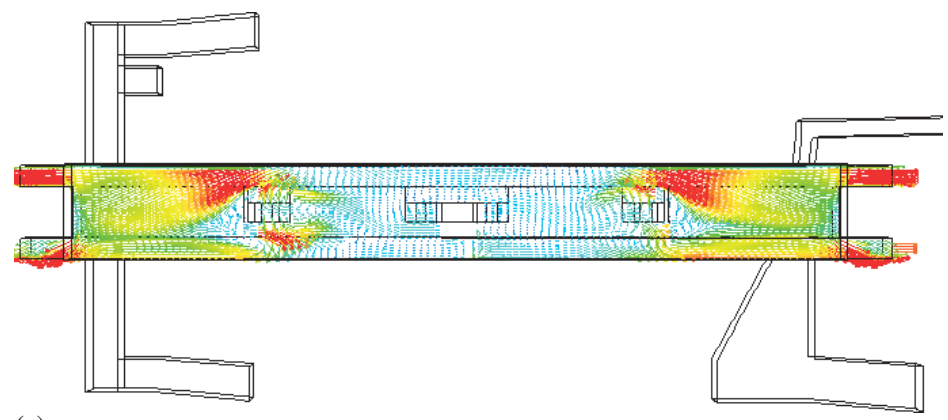

(a)

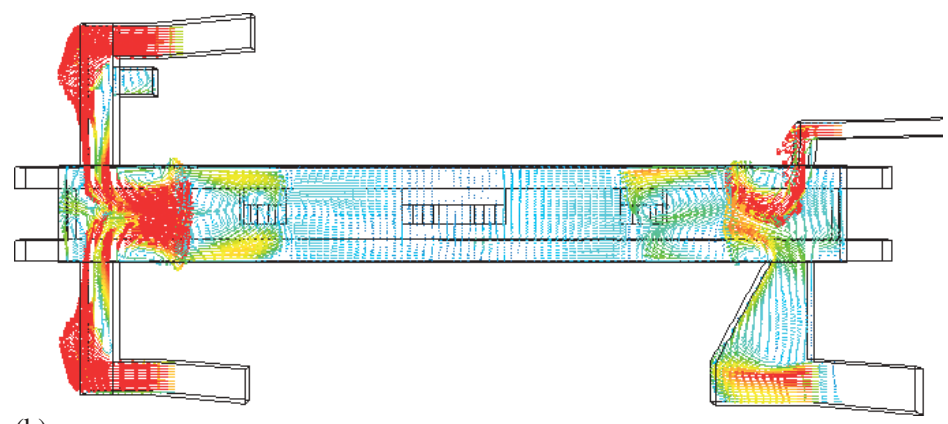

(b)

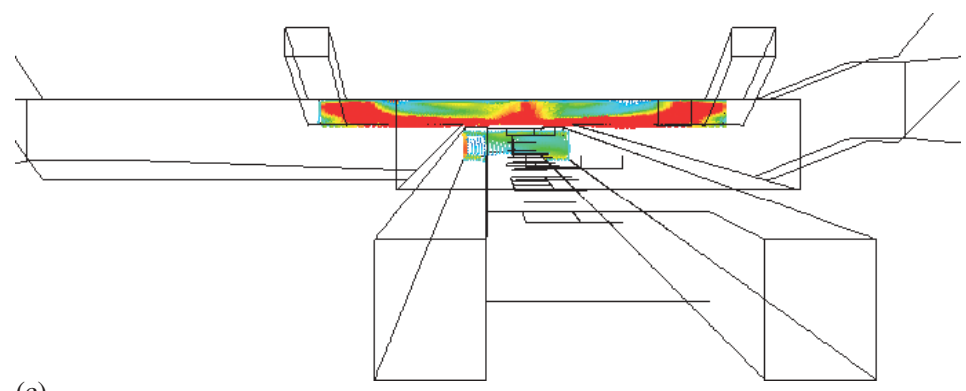

(c)

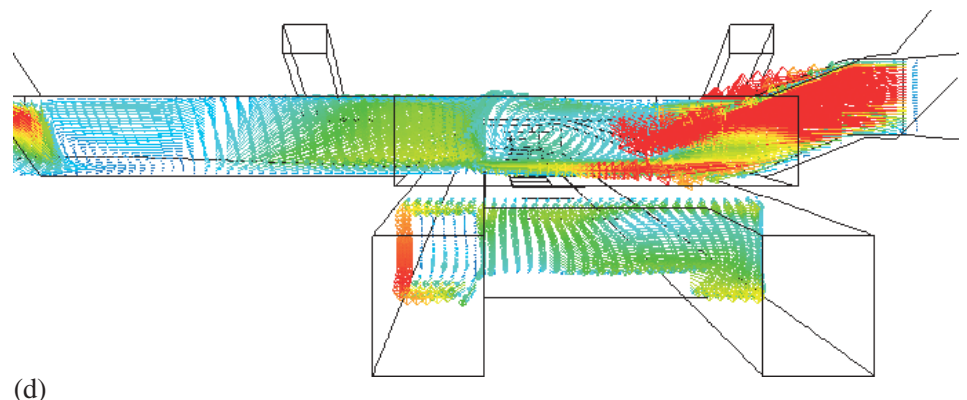

Figure 7. Velocity vectors in different cross-sectional planes at $t=6 \mathrm{~min}$. The fire occurs at the center of the platform floor, all TVF, UPE, and SEG are active. (a) The HCS plane is $2 \mathrm{~m}$ above the platform floor. Due to the strong suction of the TVF, the flow velocities in the four tunnels are as high as $5 \mathrm{~m} / \mathrm{s}$, and so are the flows in the vicinity of the two escalators moving down from the lobby floor to the platform floor. (b) The HCS plane is $2 \mathrm{~m}$ below the ceiling. Strong streams of fresh air move through the four exits into the station. (c) The VCS plane is at the center of the left lobby. A strong streams of fresh air move into the left lobby. (d) The VCS plane is at the center of the right lobby. A strong stream of fresh air moves through Exit D into the station.

HCS plane $1 \mathrm{~m}$ below the ceiling, one can see that the SBW serves nicely to limit the smoke within the two smoke zones at the center. It is also seen from Figure $6 \mathrm{D}(\mathrm{b})$, the smoke distribution on the HCS plane $4 \mathrm{~m}$ above the platform floor, that most of the smoke is evacuated through the tunnel below Exit D.

To illustrate more clearly the power of the TVF and UPE, we show in detail the flow structure of Figure $6 \mathrm{C}(\mathrm{d})$ where the smoke is well controlled under the action of the TVF and UPE. Figure 7(a) shows the 
velocity vectors in an HCS plane $4 \mathrm{~m}$ above the platform floor. It is seen that strong winds (orange vectors) are induced near the two stairs and the four tunnels, which is obviously due to the strong suction from the TVF and UPE inducing the fresh air to come down from the lobby floor through the cut-off area of the lobby floor. Figure 7(b) shows the velocity vectors in an HCS plane $1 \mathrm{~m}$ below the ceiling, confirming that fresh air is sucked into the station through the four stairwells. Note that the induced flow in Exit $\mathrm{C}$ is smaller than the others because of its larger cross-sectional area. Figure 7(c),(d) shows the VCS planes on respectively the left and the right of the station, again indicating that the strong winds induced by the suction of the TVF and UPE pass through the stairwells rapidly.

The above results indicate invariably that the TVF and UPE of GGSS can control the smoke generated by a fire occurring in the center of the station, and the SEG is an auxiliary equipment helping evacuate the smoke attached to the ceiling. Regarding the case of a fire occurring at the two ends of the lobby floor, the natural convection due to the stack effect can serve well to evacuate the smoke through the nearby stairwells. For the case of a fire occurring at the two ends of the platform floor, the TVF can drive all the smoke into the tunnels near the fire, leaving both the platform and the lobby floors free of smoke [1]. Present results also suggest that the existing smoke control schemes can meet the 6 min critical limit of NFPA since the smoke can always be well controlled from the beginning of fire so that it does not move into the four exits. Thus the passes for passengers to evacuate the station are all free of smoke, and they can move smoothly and leave without disturbance due to smoke.

\section{Effects of the Platform Edge Door on Smoke Control}

The platform edge door (PED) is a vertical wall made of a transparent material such as reinforced plexiglass, partly or completely separating the spaces between the platform and the rails. On this transparent wall there are as many doors as on the train, both sets of doors are aligned in exactly the same position and are controlled automatically in the same phase; namely, they open or close simultaneously. The concept of the PED has been widely accepted in modern subway systems, and has also been set up in many new metropolitan subway systems, such as those in Hong Kong, Singapore, the London Jubilee line (Figure 8(a)), and so on. The motivation for setting up a PED is primarily due to passenger safety requirements and partly due to air condition energy savings. In fact, the latter factor is becoming more important to countries in a tropical or subtropical region, such as those in South-East Asia, where an air condition system is definitely required. For GGSS, for example, although currently there is no PED setup (Figure 8(b)), the authority is considering building a full-height PED. With a PED, according to the preliminary design data, GGSS can save more than $35 \%$ of the air condition energy consumed without a PED [1]. There is another benefit of PED: it will purge the flow in the station caused by the piston effect of the train approaching the station [12], which induces an approximately $6 \mathrm{~m} / \mathrm{s}$ wind (usually containing oil-smelling air) into the station, making passengers feel uncomfortable. In this section we investigate from a safety point of view the effect of a PED on smoke control if a fire occurs GGSS. The PED considered is a full-height style and has 14 doors on each side of the platform,

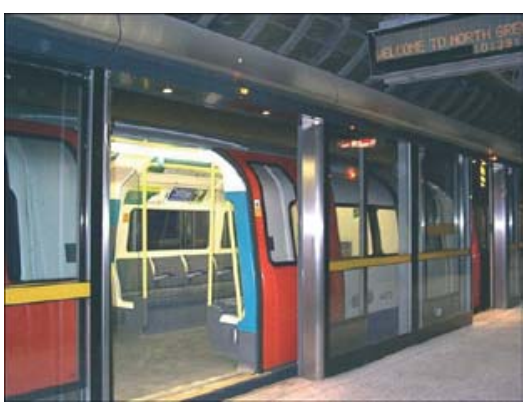

(a)

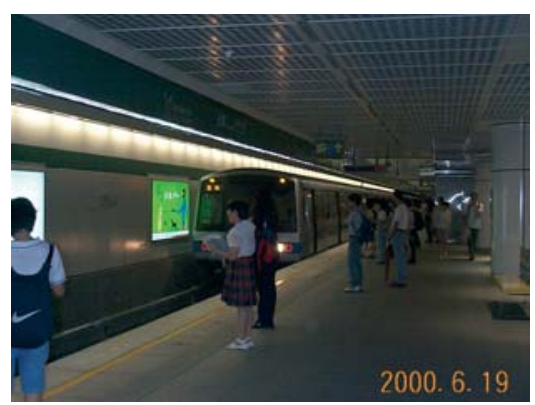

(b)

Figure 8. (a) The PED of a subway station on the Jubilee line of the London subway system. (b) The platform floor of GGSS without a PED. 
as many as a train consisting of seven wagons has. Each door is approximately $4.5 \mathrm{~m}$ wide, being as wide as those of train.

\subsection{Comparison Between Cases with and Without a PED}

Figure 9 shows the smoke distribution on different cross-sectional planes for cases with and without a PED when the fire occurs in a position $4 \mathrm{~m}$ left of the center of the platform floor. In both cases, the smoke control schemes TVF, UPE, and SEG are active. For the case with a PED, all 28 doors are opened so that the smoke can move into the tunnels through these doors. Figure 9(a),(d) shows the smoke distribution on the middle VCS plane without and with a PED, respectively. Both cases show that the smoke is largely confined to the central part of the station, and most of the smoke is evacuated from the two tunnels at the right of the station. Figure 9(b),(e) shows respectively the smoke distribution without and with a PED on the HCS plane $1 \mathrm{~m}$ below the ceiling when, due to the effect of the SBW, the smoke is mostly blocked within the central part of the station. Figure 9(c),(f) shows again for the two cases the smoke distribution on the HCS plane $4 \mathrm{~m}$ above the platform floor. In Figure 9(f) one can see the detailed flow structure of the smoke passing through the doors of the PED into the rail space, showing that the computational grid is fine enough to reflect the important features of the flow.

Results of Figure 9 imply that the appearance of a PED does not influence smoke control significantly when a fire occurs on the platform. However, a slight difference can also be seen: the smoke temperature is lower in the case with a PED. This is because with a PED the suction force from the TVF is enhanced since the suction is concentrated on the 28 PED doors, rather than without any concentration as in the case without a PED. With this outcome, we propose a very efficient smoke control scheme with a PED in the following.

\subsection{An Effective Scheme Utilizing a PED to Control Smoke}

With a PED, as shown in Figure 9(f), the suction force due to the TVF is reflected in that the smoke in the station will pass through the doors of the PED and move into the tunnels to evacuate. Since there are a total of

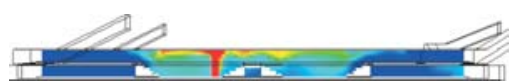

(a)

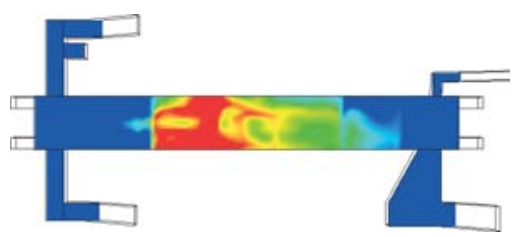

(b)

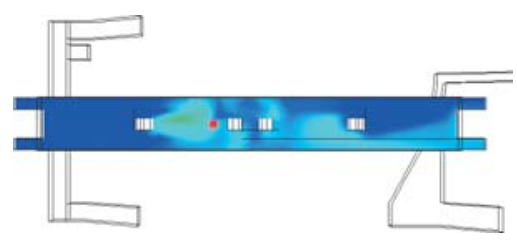

(c)

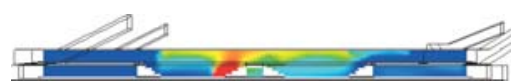

(d)

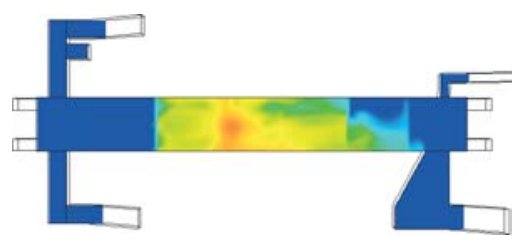

(e)

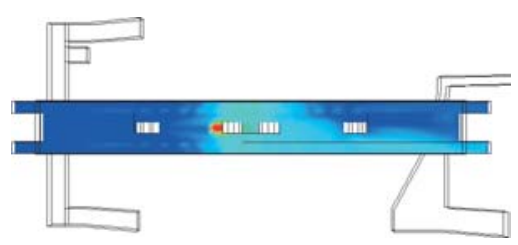

(f)

Figure 9. A comparison between smoke distributions in GGSS with and without a PED. The fire occurs at the center of platform, all the smoke control schemes, TVF, UPE, and SEG, are active. (a)-(c) Smoke distributions at $t=40 \mathrm{~s}$ on the VCS plane at the middle of the station, on the HCS plane $1 \mathrm{~m}$ below the ceiling, and on the HCS plane $2 \mathrm{~m}$ above the platform floor, respectively; all are for the case without a PED. (d)-(f) The same cross-sectional planes with a PED, where all the doors are opened so that the smoke can be sucked into the tunnels through the doors by the TVF. (f) The smoke passes through each door due to the TVF. 


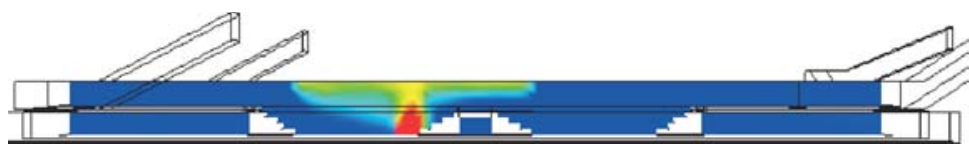

(a)

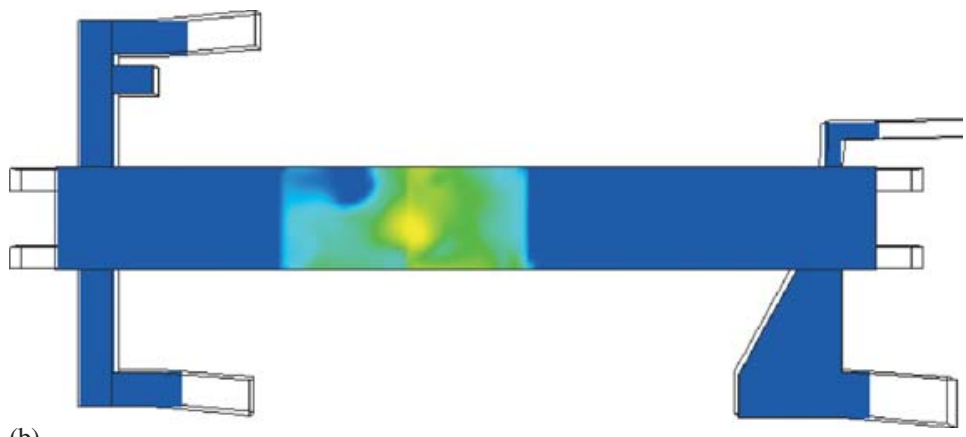

(b)

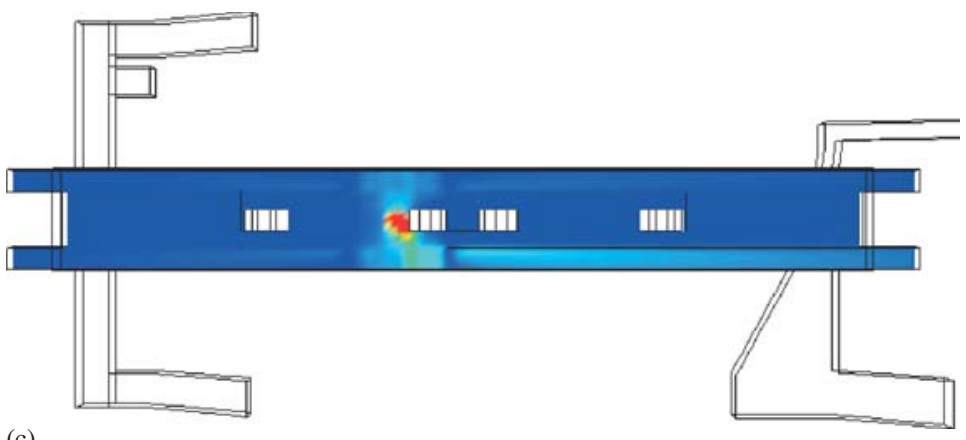

(c)

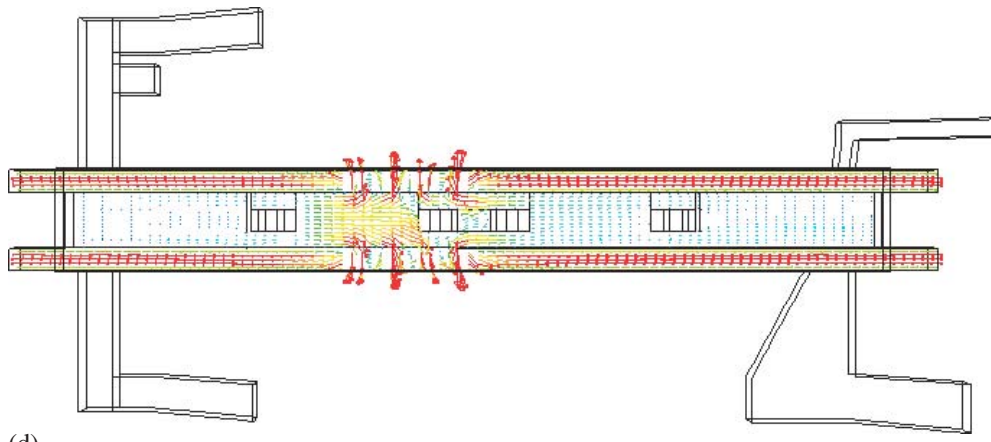

(d)

Figure 10. Smoke flow in GGSS at $t=40 \mathrm{~s}$ when only eight selected doors near the fire are opened. The fire occurs near the center of the platform floor, all TVF, UPE, and SEG are active. (a) Smoke distribution on the VCS plane at the middle of the station. (b) Smoke distribution on the HCS plane $1 \mathrm{~m}$ below the ceiling. (c) Smoke distribution on the HCS plane $2 \mathrm{~m}$ above the platform floor. (d) The velocity vectors corresponding to (c).

28 doors along platform, the suction force is therefore divided into as many parts as the number of doors and distributed along the platform, so that there is still a significant amount of smoke left in the station. If only a few doors are opened during the fire, the suction force can therefore be more concentrated and stronger, and smoke evacuation can be done more efficiently. Based on this idea, we proposed a scheme where only a few doors near the fire are opened when a fire occurs on the platform. A typical result is shown in Figure 10, in which a fire occurs on the platform, located $4 \mathrm{~m}$ left of the center, and only the eight doors of the PED near the fire are opened, and all three smoke control systems are turned on. Results show that, by comparing Figure 10(a)-(c) (selected doors opened) with respectively Figure 9(d)-(f) (all doors opened), the smoke is sucked out of the platform floor in a much more efficient way, leaving only a much smaller amount of smoke 
in the station. One can also see from the velocity vectors of Figure 10(d) that strong winds are induced to pass through the eight open doors, sucking the smoke into the tunnels efficiently.

\subsection{Smoke Control when a Train is on Fire}

The most dangerous case of fire is when the train is on fire and moves into the station. Under such circumstances, the train should stop in the station and open the doors of the train as well as those of the PED to evacuate the passengers in the shortest possible time. Smoke control becomes complicated since the smoke may move with the passengers into the platform floor or even the lobby floor since all the doors are open. We examined this case and the results are shown in Figure 10. In these computations, the train in the computational domain is seen as a combination of seven empty rectangular boxes. Each box accounts for a wagon, in which two doors are opened on the boundary of the box facing the platform. As a result, the box has two open areas through which the smoke can pass.

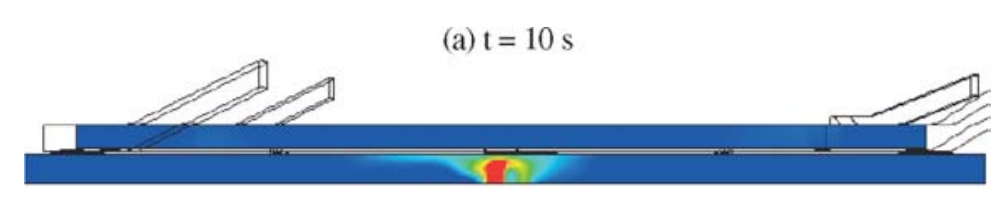

(b) $\mathrm{t}=30 \mathrm{~s}$

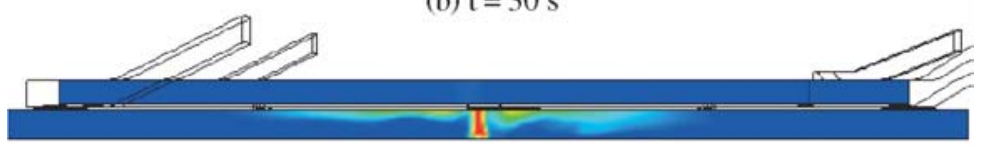

(c) $\mathrm{t}=1 \mathrm{~min}$

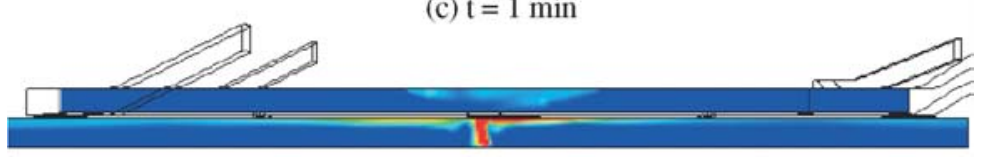

(d) $\mathrm{t}=2 \mathrm{~min}$

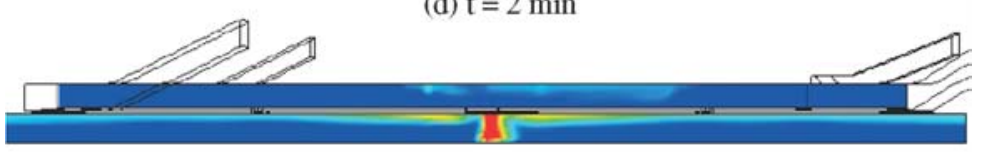

(e) $\mathrm{t}=3 \mathrm{~min}$

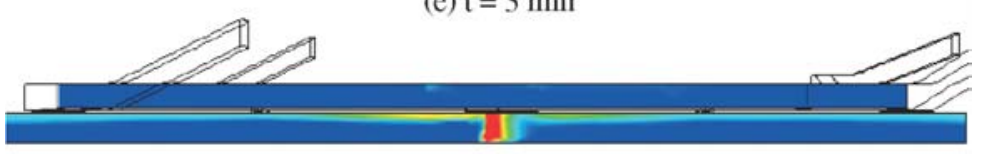

(f) $\mathrm{t}=5 \mathrm{~min}$

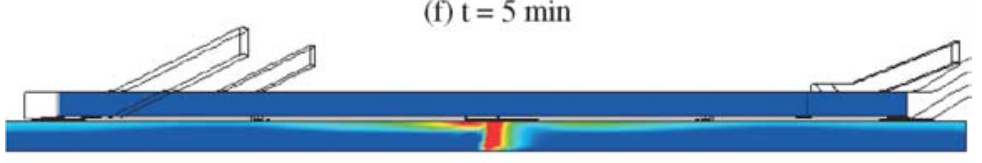

(g) $\mathrm{t}=10 \mathrm{~min}$

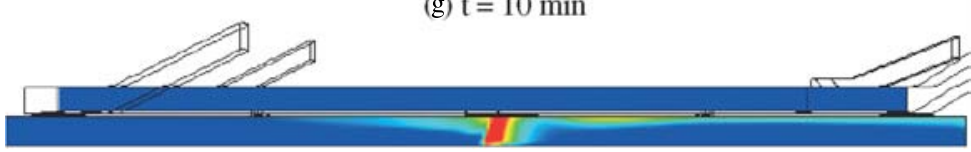

Figure 11. Smoke propagation in GGSS with a PED when a fire occurs on the chassis of the central wagon of a train. The VCS plane is located $0.25 \mathrm{~m}$ from the wall of the tunnel. It is seen that the smoke moves along the ceiling of the tunnel, being sucked into the tunnels by the TVF at the two sides of the station. 
(a) $\mathrm{t}=10 \mathrm{~s}$

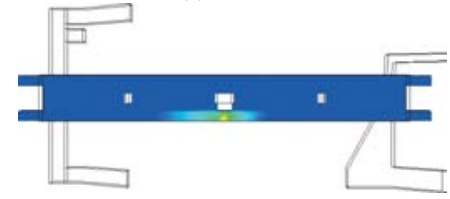

(b) $\mathrm{t}=30 \mathrm{~s}$

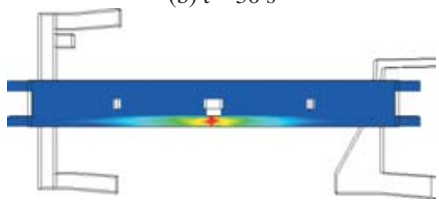

(c) $\mathrm{t}=1 \mathrm{~min}$

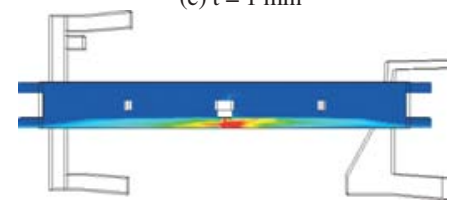

(d) $t=2 \min$

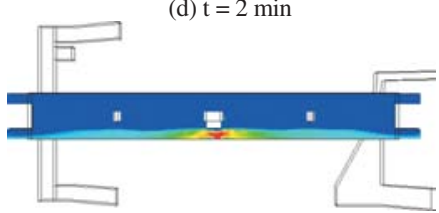

(e) $\mathrm{t}=3 \mathrm{~min}$

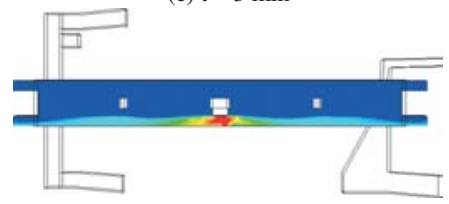

(f) $\mathrm{t}=5 \mathrm{~min}$

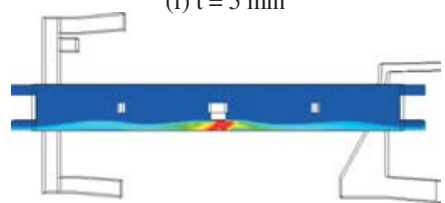

(g) $\mathrm{t}=10 \mathrm{~min}$

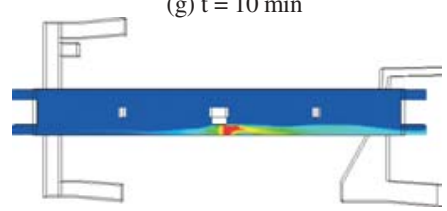

Figure 12. The same case as Figure 11, with the HCS plane located $2 \mathrm{~m}$ above the platform floor. The smoke is well restricted in the tunnel space, due both to the suction of the TVF and the existence of a PED.

(a) $t=10 s$

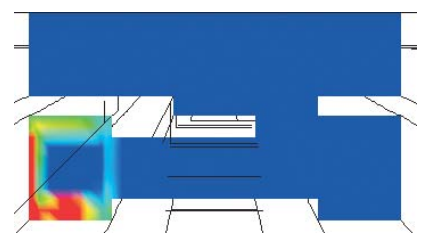

(b) $\mathrm{t}=30 \mathrm{~s}$

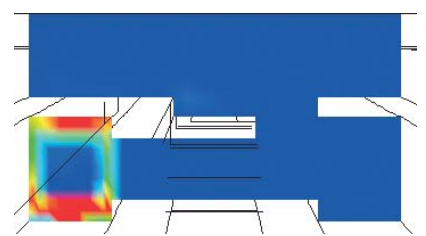

(c) $\mathrm{t}=1 \mathrm{~min}$

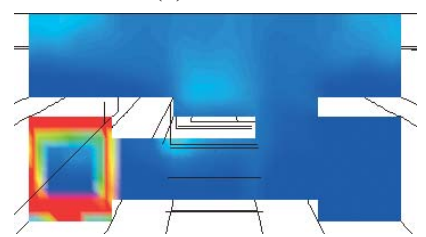

(d) $\mathrm{t}=2 \min$

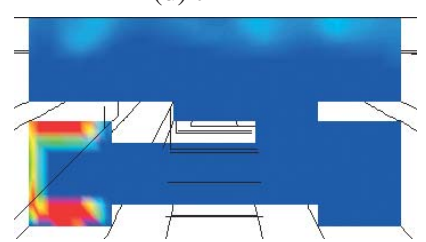

(e) $t=3 \min$

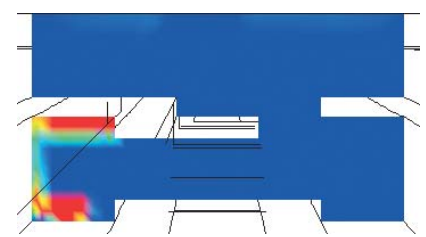

(f) $\mathrm{t}=5 \mathrm{~min}$

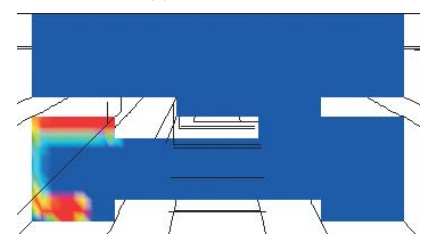

(g) $\mathrm{t}=10 \mathrm{~min}$

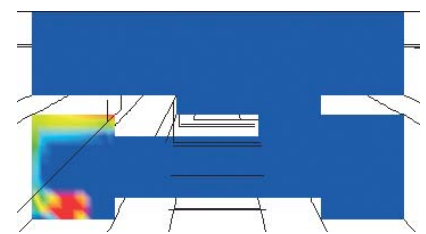

Figure 13. The same case as Figure 11, the VCS plane cuts through the center of the wagon on fire. All the doors of the PED and the train are opened to evacuate the passengers. It is seen that only a small amount of smoke moves into the station. 
(a) $\mathrm{t}=10 \mathrm{~s}$

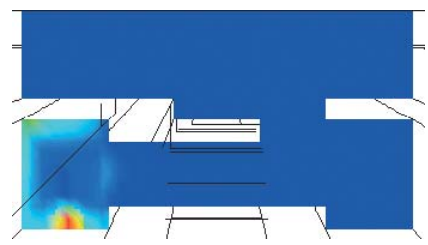

(b) $\mathrm{t}=30 \mathrm{~s}$

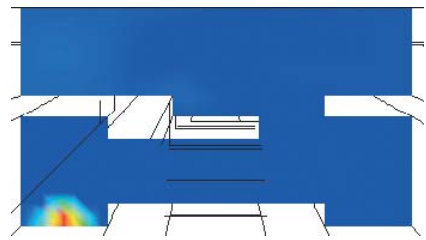

(c) $\mathrm{t}=1 \mathrm{~min}$

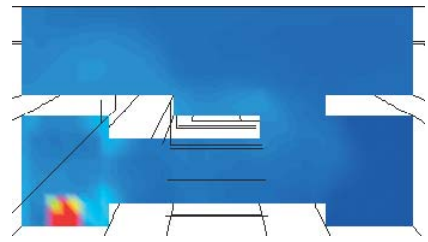

(d) $t=2 \min$ (e) $t=3 \min$

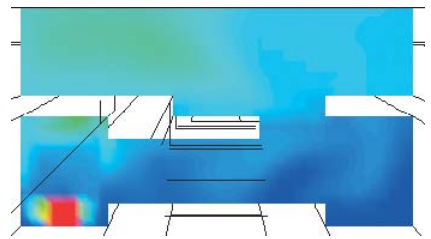

(f) $\mathrm{t}=5 \mathrm{~min}$

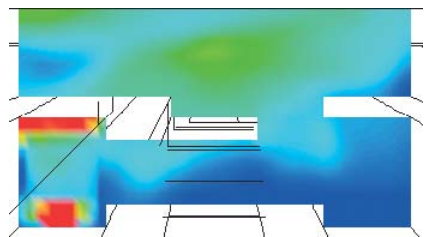

(g) $\mathrm{t}=10 \mathrm{~min}$
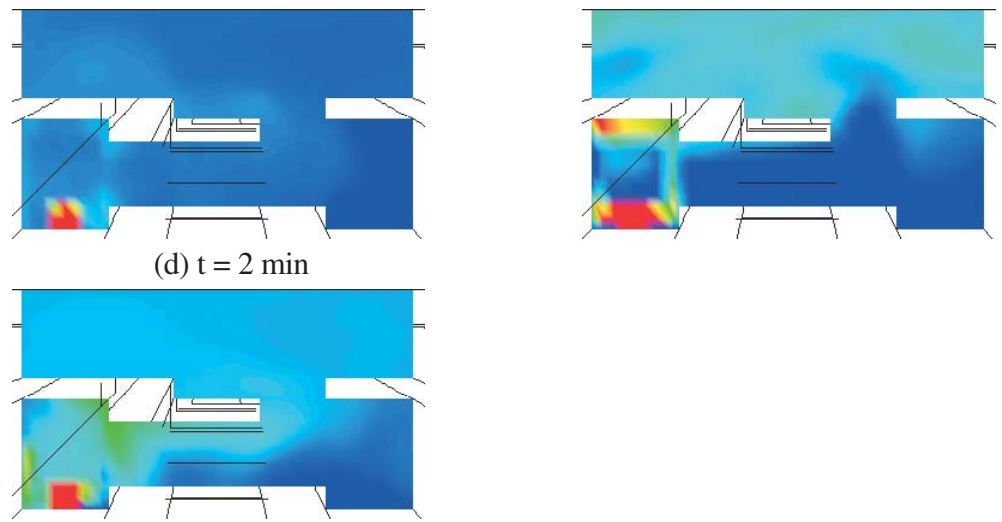

Figure 14. A comparison case with Figure 13 without a PED. A large amount of smoke moves into the station, the suction of the TVF is not as effective as that of Figure 13.

To examine the performance of the smoke control schemes of GGSS under such circumstances, we consider that a $10 \mathrm{MW}$ fire [11] occurs on the chassis of the central wagon of the train, all the doors of train and the PED are opened and the TVF, UPE, and SEG are all active. A side view of the smoke propagation along the tunnel is shown in Figure 11, where the VCS plane is located $0.25 \mathrm{~m}$ from the tunnel wall, sitting between the wall and the train body. It is seen that the smoke is attached to the ceiling of tunnel, being sucked by the TVF located at the two ends of the station. Only a small amount of smoke leaks to the lobby floor, as shown in Figure 11(c),(d). The top view of the smoke propagation along the tunnel (Figure 12) is shown on an HCS plane $4 \mathrm{~m}$ above the platform (higher than the train but lower than the ceiling of the tunnel), which shows again that smoke is largely restricted within the rail space while it is rarely seen in the platform floor. We also show in Figure 13 the smoke propagation in a VCS plane cutting through the center of the wagon on fire as well as the center of the station (end view). It is seen that, at $t=10 \mathrm{~s}$, the train has been surrounded by smoke; at $t=1 \mathrm{~min}$, a small amount of smoke has moved into both the station and the train since all the doors are open. However, nevertheless, afterwards the smoke is rapidly sucked out of both the station and the train, moving into the tunnels by way of the TVF.

Although the doors of the PED are opened when the train is on fire, the existence of a PED is still helpful for smoke control because it will to some extent block the smoke of the train from moving into the station. To illustrate this scenario, we show in Figure 14 the case without a PED when the train is on fire, corresponding to the case of Figure 13. By comparing Figures 13 and 14, one can immediately clearly see that without a PED the smoke moves rapidly into the station, making smoke control much more difficult than is the case with a PED. Note also that the efficient smoke control scheme, i.e., the selected-door-opened scheme, cannot be used in the case when a train is on fire because all the doors of the train and the PED must be opened to evacuate the passengers at the beginning. Then all the doors must be left opened for a few minutes (for example, $6 \mathrm{~min}$ ) to ensure all the passengers have left the train. 


\section{Concluding Remarks}

We have employed a CFD technique to investigate the propagation of smoke generated by various kinds of fires occurring at GGSS of the TRTS. A three-dimensional computational domain fitting the interior of GGSS is set up (see Figure 1), in which three mechanical smoke control schemes, TVF, UPE, and SEG, are considered by way of prescribing relevant boundary conditions. The fire is considered as a source of heat and mass, and the standard $\kappa-\varepsilon$ turbulence model is employed to account for the vigorous buoyancy-driven flow, in which both heat and mass transfers have a significant effect on the structure of the turbulent flow moving in such a complicated geometry as that of GGSS.

We first investigate the effectiveness of the smoke control systems of GGSS when fires occur in different locations. Results suggest that: (1) When a fire occurs at the two ends of the lobby floor, the stack effect will predominate smoke propagation and the smoke will evacuate through the stairwell(s) near the fire; no mechanical smoke control is needed. (2) When a fire occurs in the central area of the platform floor, the buoyant flow will move upwards rapidly, impinging on the ceiling and spreading into every corner of the station. Under such circumstances, all three mechanical smoke control systems shall turn on, then most of the smoke will be sucked out of the station through the TVF and the UPE and a small amount of smoke will evacuate through the SEG, leaving the four exits through which the passengers are supposed to evacuate the station free of smoke. (3) When fires occur at the two ends of the platform floor, the smoke will also move rapidly to both the lobby and the platform floors if no mechanical smoke control is engaged, but will be evacuated from the station efficiently when the TVF close to the fire is active. In brief, with the present mechanical smoke control systems of GGSS, the smoke generated by a fire of $5 \mathrm{MW}$ can be well controlled, leaving the emergency passages free of smoke so that the passengers can evacuate the station smoothly. Note that $5 \mathrm{MW}$ is supposed to be the largest possible fire that will ever occur in a normal situation of a subway station. While a larger fire heat release rate, say $10 \mathrm{MW}$, can also be possible when a train is on fire [10], this kind of fire can also be well controlled if a suitable scheme for smoke control is applied, as shown in Section 7.3.

We also consider the effect on smoke control due to the appearance of a PED, which has been widely accepted and set up in modern subway systems, especially those in countries in tropical and subtropical regions. We consider two kinds of fire for this case: when a fire occurs on the platform and when a fire occurs on the chassis of a train. Results show that when a fire occurs at the center of the platform floor, according to standard operation procedure all the doors of the PED should be opened, the smoke can be sucked out of the platform floor by the TVF. For the same fire, we propose a new scheme for smoke control: open only a few doors of the PED near the fire. Consequently, due to the fact that the suction force from the TVF is concentrated on only a few opened doors, the smoke will be efficiently evacuated from the station under the action of the TVF. When a fire occurs on the chassis of train, usually a $10 \mathrm{MW}$ fire, the existence of a PED (although all the doors are opened) helps restrict the smoke within the rail space and the tunnel, making smoke control much easier than when without a PED.

In conclusion, under the current smoke control schemes employed in GGSS, all passengers can be safely evacuated from the station within a reasonable time, usually less than the 6 min necessary to fit the NFPA regulation, when a normal fire accident happens. A more efficient smoke control scheme is available when a PED is set up in the station. If only the standard operation procedure can be implemented normally in fire accidents, the safety of passengers in GGSS can be guaranteed. Since GGSS is quite typical of modern subway station design and its smoke control systems are also standard, we believe that the present conclusions may to some extent also be valid for other subway station of a similar configuration.

\section{References}

[1] Chen, F., and Chien, S.W. (2001). Development of escape model for passengers and analysis of shortest allowable evacuation time in subway stations of TRTS. Project Report, SinoTech Engineering Consulting Company, Taipei.

[2] Simcox, S., Wilkes, N.S., and Jones, I.P. (1988). Fire at King's Cross underground station on $18^{\text {th }}$ November 1987: numerical simulation of the buoyant flow and heat transfer. AERE-G 4677, UK.

[3] Zukoski, E.E. (1995). A review of flows driven by natural convection in adiabatic shafts. Report No. NIST-GCR-95-679, USA.

[4] Chang, W.J. (2001). Smoke propagation and stack effect in fires in subway stations. Master thesis, National Taiwan University, Taipei, Taiwan.

[5] Chen, F. (2000). Smoke propagation in road tunnels. ASME Appl. Mech. Rev., 53, 207-218. 
[6] Malhotra, H.L. (1995). Goods vehicle fire test in a tunnel. Proc. 2nd Int. Conf. on Safety in Road and Rail Tunnels, 3-6 April 1995, Granada, Spain. Paper No. 28, pp. 237-244.

[7] Libby, P.A., and Williams, F.A. (1994). Fundamental aspects and a review. In Turbulent Reacting Flows (P.A. Libby and F.A. Williams, eds.), Academic Press, London.

[8] Liu, F., and Wen, J.X. (2002). The effect of turbulence modeling on the CFD simulation of buoyant diffusion flames. Fire Safety J., 37, 125-150.

[9] Markatos, N.C., Malin, M.R., and Cox, G. (1982). Mathematical modeling of buoyancy-induced smoke flow in enclosures. Int. J. Heat Mass Transfer, 25, 63-75.

[10] Ingason, H. (1994). Heat release rate measurements in tunnel fires. Proc. Int. Conf. on Fires in Tunnels, 10-11 October 1994, Boras, Sweden, pp. 86-103,

[11] NFPA (1997). Standard for Fixed Guide Way Transit System. National Fire Protection Association 130, USA.

[12] Mendonca, F. (1996). Computational fluid dynamics (CFD) analysis of a decelerating train entering an underground station. Proc. 1st Int. Conf. on Computer Application in Transportation Systems, 24-26 June 1996, Basel, Switzerland, pp. 89-100. 